\title{
Optimization of Electronically Monitored
}

\section{Non-Adherence in Highly Adherent Renal Transplant Recipients by Reducing the Dosing Frequency - A Prospective Single-Center Observational Study}

This article was published in the following Dove Press journal:

Patient Preference and Adherence

\author{
Marietta Lieb (iD ${ }^{1}$ \\ Mario Schiffer ${ }^{2}$ \\ Yesim Erim ${ }^{\prime}$ \\ 'Department of Psychosomatic Medicine \\ and Psychotherapy, Friedrich-Alexander- \\ University Erlangen-Nürnberg (FAU), \\ Erlangen, Germany; ${ }^{2}$ Department of \\ Nephrology and Hypertension, \\ University Hospital of Erlangen, Erlangen, \\ Germany
}

Background: Non-adherence (NA) after renal transplantation poses a major risk for allograft rejection, graft loss, and patient mortality. Yet, there is still ambiguity about its etiology and its possible relationships with patient-related factors. In order to prevent poor outcomes after transplantation, it is crucial to gain a more refined understanding of potential determinants, to identify patients at risk, and to intervene accordingly. The objective of this study was to assess potential risk factors of NA by prospectively applying electronic monitoring. Materials and Methods: This was a single-center prospective observational study. Prior to study initiation, sociodemographic, biomedical, and psychosocial variables (depression, healthrelated quality of life, self-efficacy, social support, attachment, experiences and attitudes towards immunosuppressive medication, emotional responses after organ transplantation, satisfaction with information about immunosuppressive medication, and perceptions and beliefs about medications) were assessed. Thereafter, immunosuppressive adherence behavior was measured prospectively via electronic monitoring (EM, VAICAC) during a 3-month period to receive the percentage frequency of Taking and Timing Adherence $( \pm 2 \mathrm{~h}, \pm 30 \mathrm{~min})$ for each patient. Focus of this study was the phase of medication implementation.

Results: A total of 78 patients participated in our study (mean age $55.28,56 \%$ male). We found rates of $99.39 \%$ for Taking Adherence, $98.34 \%$ for Timing Adherence $\pm 2 \mathrm{~h}$, and $93.34 \%$ for Timing Adherence $\pm 30 \mathrm{~min}$, respectively. Multiple regression analyses revealed that the type of medication could significantly predict Taking Adherence. Patients receiving Advagraf(C) (once daily) depicted better Taking Adherence than patients receiving Prograf(C) (twice daily) ( $\mathrm{p}=0.04)$. No associations were found for Timing Adherence $( \pm 2 \mathrm{~h}, \pm 30 \mathrm{~min})$. Sociodemographic, biomedical, or psychosocial variables were not found to be associated with adherence behavior.

Discussion: In highly adherent populations, only a few factors can be altered to improve adherence. Changing the immunosuppressive regimen from twice-daily to once-daily could be an option for optimizing adherence. However, risk factors for NA could be different in a less adherent population.

Keywords: adherence, patient-related factors, psychosocial variables, electronic monitoring, immunosuppressive medication

\section{Background}

Vrijens et $\mathrm{al}^{1}$ define adherence as "the process by which patients take their medications as prescribed". Despite its hazardous impact on allograft rejection,
Correspondence: Marietta Lieb Department of Psychosomatic Medicine and Psychotherapy, University Hospital of Erlangen, Schwa

Tel +49-9I3I-8545930

Email Marietta.Lieb@uk-erlangen.de
Patient Preference and Adherence 2020:14 |389-|40|

mit your manuscrip in $\square$ 
graft loss, and patient mortality, ${ }^{2-4}$ non-adherence (NA) to immunosuppressive medication is a common phenomenon in renal transplant recipients. Even minor deviations are considered to have harmful effects on organ survival, ${ }^{5}$ yet mean prevalence rates vary around $35.6 \%$ of patients per year. ${ }^{6}$ In order to prevent NA in the first place, it is crucial to examine its reasons and risk factors that can be targeted during professional interventions. So far, recent research suggests beneficial effects of interventions on adherence behavior in renal transplant recipients. ${ }^{7-10}$ Overall, multidimensional interventions are considered more effective than single-component ones in improving medication adherence. ${ }^{10,11}$ Especially individualized interventions that comprise a combination of behavioral, educational, and emotional components seem promising. ${ }^{10}$ However, there is still insufficient knowledge about which components are most effective and what specific patient-related factors must be targeted to optimize adherence. ${ }^{11}$ Since medication adherence is a complex phenomenon characterized by an interplay of a variety of factors, ${ }^{11}$ a more comprehensive understanding of potential determinants is necessary to identify patients at risk and to develop more refined interventions that are tailored to the specific needs of each patient.

When developing interventions, there is a particular need for identifying modifiable patient-related factors. A sound theoretical model that comprises factors on the individuallevel and is often cited in the context of adherence is the Health Behavior Model. Health belief theory postulates that health behavior results from individual cost-benefit evaluations of adverse health outcomes and the specific actions that are necessary to prevent these outcomes. ${ }^{12}$ In this context, factors such as negative beliefs and attitudes towards medication or treatment, ${ }^{13-16}$ as well as adherence barriers ${ }^{14,16,17}$ were previously examined and found to be significantly associated with adherence behavior. However, various other patient-related factors have been linked to medication NA in renal transplant recipients as well, such as depression, ${ }^{13,15,18-20}$ anxiety, ${ }^{13,18}$ sex, ${ }^{21-23}$ education, ${ }^{20,21}$ marital status, ${ }^{13,24}$ lower self-efficacy, ${ }^{22,25,26}$ avoidant attachment, ${ }^{27}$ lower social support, ${ }^{18,21,28,29}$ lower quality of life, ${ }^{14,28}$ non-white ethnicity, ${ }^{4,20}$ higher frequency of medication intake, ${ }^{30-34}$ type of renal graft, ${ }^{20,35}$ longer time since transplantation, ${ }^{20,23,36}$ and younger age. $2,4,20,24,28,36$

Still, there are many contradictory findings in the current research, due to different measurement methods of NA. ${ }^{28}$ A bandwidth of direct and indirect measurement methods for NA has emerged lately: Direct measures include direct observation, measurement of immunosuppressive (IS) levels or biomarkers in the blood, whilst indirect measures comprise pill counts, self-reports, physicians' reports, pharmacy records, or electronic monitoring (EM) ${ }^{37,38}$ Although EM is viewed as expensive and labor-intensive, ${ }^{37,38}$ a growing body of research has pursued the implementation of this method. ${ }^{8,22,39,40}$ Functional errors, induced intervention effects, and problems with utilization might constitute reasons for measurement inaccuracy. ${ }^{41-45}$ Although highly debated, some research considers EM the best measure of adherence currently available. ${ }^{4,11,46}$ To our knowledge, most studies rely on self-reports, physician's estimates, or IS levels in the blood when examining possible determinants for NA, ${ }^{13,15,17,18,21,23,25-28,36}$ whilst only a few have examined this association by applying EM. ${ }^{22,24,30,31,35}$

Therefore, the aim of this study was to investigate the associations between electronically monitored adherence and patient-related factors in order to unravel the etiology of adherence as well as to optimize future adherence interventions.

\section{Materials and Methods Design, Sample and Setting}

This was a prospective, single-center observational study and is part of the APT (Adherence and Psychological Health after Transplantation) research project of the Department of Psychosomatic Medicine and Psychotherapy. The study was conducted in cooperation with the Department of Nephrology and Hypertension at the University Hospital in Erlangen. Recruitment took place at the nephrologic outpatient clinic from March 2018 to April 2019. Potential participants were informed about the study prior to their regular follow-up appointment. Questionnaires and the electronic pillbox were handed out to interested patients during their appointment. For the following 3 months, EM took place at the patients' homes. Feedback on the individual adherence behavior was optional for each participant at the end of the study. The study procedure can be viewed in Figure 1. A more extensive study design was previously published in Lieb et $\mathrm{al}^{47}$

Inclusion criteria were renal transplant recipients who were at least 18 years of age, received tacrolimus (Advagraf $($ ) or Prograf $\subset$ ) as their main immunosuppressive medication, and were at least 6 months posttransplant. Excluded were patients with insufficient German language skills, severe mental disorders, and/or 


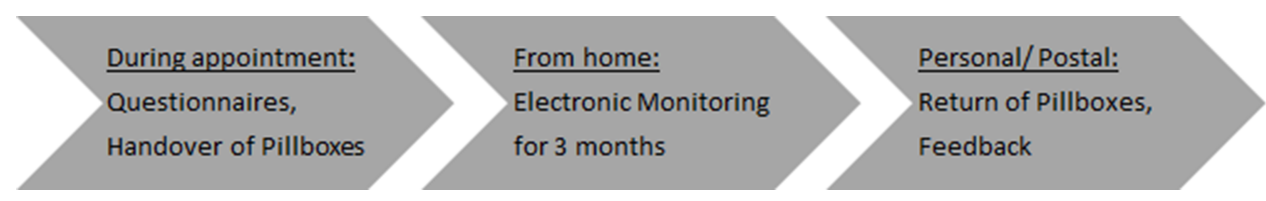

Figure I Study procedure.

cognitive impairments. Adherence behavior was no eligibility criterion. Research focus was medication implementation, whilst cases of initiation were excluded. ${ }^{1,48}$ Before study participation, written informed consent was given by all participants. Institutional ethics board approval was obtained from the Clinical Ethics Committee of the University Hospital Erlangen (FriedrichAlexander-University, Erlangen-Nürnberg, FAU).

\section{Data Collection and Measurement Methods Questionnaires}

For the assessment of psychosocial variables, the questionnaires depicted in Table 1 were applied. The choice of instruments was theory-guided and is based on the Health Belief Model. In addition, we conducted a short adherence interview with each patient comprising the following questions following the Life-Routine Model by Russell et al: ${ }^{40}$ a) Are you being supported by someone when taking your immunosuppression? b) Are you using reminders for the regular intake of your immunosuppressive medication? c) Have you linked your medication intake with certain daily routines? d) Are there obstacles in your daily life that could prevent you from taking your immunosuppression regularly and/or punctually (travel, appointments, irregular working times, going out)?

\section{Electronic Monitoring}

For the electronic assessment of immunosuppressive NA, each patient received an electronic pillbox (VAICA SimpleMed(C, Tel Aviv, Israel) for home use over the period of 3 months. Each pillbox allows the storage of medication up to 7 days and four doses a day in a total of 28 cells. The individual medication plan including the specific intake times for the main immunosuppressant (Advagraf( $\odot$ or Prograf(C) was entered on the corresponding web portal for each patient. During the study course, each opening of the pillbox cells was automatically registered. The respective pill extraction times were instantly transferred to the corresponding web-based pillbox record via cellular reception. This way, the pillbox allows a real-time surveillance of medication adherence. We only monitored the main immunosuppressive medication, to reach comparability between all patients. We monitored three adherence parameters for the course of 3 months: 1) Taking Adherence: Percentage of prescribed doses taken, 2) Timing Adherence $\pm 2 \mathrm{~h}$ : Percentage of prescribed doses taken within a 2-hour interval (according to the time interval defined by BAASIS $\left({ }^{46}\right)$, 3) Timing Adherence \pm 30 min: Percentage of prescribed doses taken within a 30-minute interval (according to the time interval recommended in our hospital). If extraction did not coincide with pill intake (eg pill is taken later) or if the medication was taken from another source, patients were asked to keep diaries in order to improve validity. ${ }^{22,64}$ We used the percentage of (on-time) taken immunosuppressants, in order to treat the two different dosing regimens (once-daily vs twice-daily) equally. The percentage of (on time) taken immunosuppressants was calculated for the whole study course ( 3 months), reaching values between $0 \%$ and $100 \%$.

\section{Data Management and Statistical Analysis}

Deficient electronic data were completed by using notes from the patients' diaries. If inconsistency of diary use was stated (ratings $\leq 5$ from a scale of $0-10$ ), repeated technical failure, incorrect pillbox use, or multiple incidents of bad reception were evident during the monitoring period, the respective patients were excluded from the analysis. ${ }^{42,44}$ If patients did not use the pillbox for a certain period (eg, travel, hospitalization, weekend, etc.), we extended the individual study period for the respective time, if it was feasible. EM-Imputations were used to replace single missing values in the questionnaires. Missing values for EM and whole psychometric scales were not replaced. We indicated the number of patients that were included in the respective analyses.

For descriptive statistics, we depicted mean values, standard deviations, and ranges. Electronically monitored adherence is depicted in percentages (\%). Timing Adherence $\pm 30 \mathrm{~min}$ includes all cases of Timing Adherence $\pm 2 \mathrm{~h}$ while Timing Adherence $\pm 2 \mathrm{~h}$ includes all cases of Taking 
Table I Measurement Methods of Psychosocial Variables

\begin{tabular}{|c|c|c|}
\hline Psychosocial Construct & Questionnaire & Information \\
\hline Depression & PHQ- $9^{49,50}$ & Self-report screening instrument of depression, 9 Items, 4-point scale \\
\hline Perceived Social Support & FSozU-7 $^{51}$ & $\begin{array}{l}\text { Self-report instrument on social support (practical support, emotional support, } \\
\text { social integration), Short form of F-SozU, } \\
7 \text { items, } 5 \text {-point scale }\end{array}$ \\
\hline Perceived Health Related Quality of Life & $\begin{array}{l}\text { WHOQoL- } \\
\text { BREF }^{52}\end{array}$ & $\begin{array}{l}\text { Self-report instrument on perceived health related quality of life (physical health, } \\
\text { psychological health, social relationships, environment), short from of } \\
\text { WHOQoL-100, } 26 \text { items, 5-point scale }\end{array}$ \\
\hline Self-Efficacy & $S W E^{53,54}$ & Self-report questionnaire, 10 Items, 4-point scale \\
\hline Attachment & $\mathrm{RSQ}^{55,56}$ & Self-report questionnaire, 30 Items, 5-point scale \\
\hline $\begin{array}{l}\text { Subjective Experiences and Attitudes } \\
\text { Towards Immunosuppressive Medication }\end{array}$ & $\mathrm{MESI}^{57}$ & Self-report questionnaire, 7 Items, 5-point scale \\
\hline $\begin{array}{l}\text { Emotional Responses After Organ } \\
\text { Transplantation }\end{array}$ & $\mathrm{TxEQ}^{58,59}$ & $\begin{array}{l}\text { Self-report questionnaire on emotional responses after Tx (guilt, worry, } \\
\text { disclosure, adherence, responsibility), } 23 \text { Items, 5-point scale }\end{array}$ \\
\hline $\begin{array}{l}\text { Satisfaction with Information About } \\
\text { Immunosuppressive Medication }\end{array}$ & SIMS-D $D^{60,61}$ & Self-report questionnaire, 17 Items, 5-point scale \\
\hline $\begin{array}{l}\text { Perceptions of and Beliefs About } \\
\text { Medications }\end{array}$ & $\mathrm{BMQ}^{62,63}$ & Self-report questionnaire, 18 items, 5 -point scale \\
\hline
\end{tabular}

Adherence. For correlations, we used the Pearson coefficient $\mathrm{r}$, for group comparisons we applied $\mathrm{Chi}^{2}$-Tests. In the case of highly skewed distributions, we used Mann-WhitneyU-Tests for group comparisons and Kendall's tau for correlations. Three multiple regression analyses were conducted with Taking Adherence, Timing Adherence $\pm 2 \mathrm{~h}$, and Timing Adherence $\pm 30 \mathrm{~min}$ as outcome variables, respectively. We used Bootstrap Confidence Intervals with 10,000 iterations in case of severe deviations from the normal distribution. Data were processed and analyzed using the software SPSS 21 for Microsoft Windows $\subset$.

\section{Results}

Of 184 contacted patients, 78 participated in our study (42.39\% Response-rate). Sickness, lack of time, and impracticability of the pillbox were reasons for nonparticipation. No differences were found between Responders and Non-Responders concerning age, year of transplantation, and sex ( $p>0.05$, see also Lieb et $\mathrm{al}^{47}$ ).

Of the 78 participants, only two patients dropped out before study completion (2.56\%). Due to improper pillbox use and/or poor reception, which leads to an untenable amount of missing data, we had to discard the data of 11 patients (14.47\%). For a total of 65 patients, we were able to collect a complete electronic data set over the duration of the 3-month course. Figure 2 outlines patient eligibility, drop-outs and data loss.

Sociodemographic, biomedical, and psychosocial data are depicted in Table 2.

As shown in Table 3, we conducted several MannWhitney-U-Tests and Kendall's $\tau$ correlations. Neither sociodemographic variables nor biomedical data, such as type of renal graft, total number of medications, or time since last transplantation, showed any significant correlation with Taking or Timing Adherence ( $\pm 2 \mathrm{~h}, \pm 30 \mathrm{~min})$. However, we found a significant difference in Taking Adherence depending on the immunosuppressive medication $(\mathrm{U}=346.50$, $\mathrm{p}=0.01$ ). Patients receiving Advagraf $\subset$ as immunosuppressant (once-daily regimen) had better Taking Adherence than patients receiving Prograf $\subset$ (twice-daily regimen). No difference was found concerning Timing Adherence $( \pm 2 \mathrm{~h}$, $\pm 30 \mathrm{~min})$. Except for self-assessed adherence, no emotional responses after transplantation were associated with electronically monitored adherence behavior. Equally, psychosocial functioning such as depression, health-related quality of life, social support, self-efficacy, attachment, and subjective experiences and attitudes towards medication did not show any association with adherence. We further found no association between adherence and receiving support for medication intake, using reminders, linking medication intake to daily 


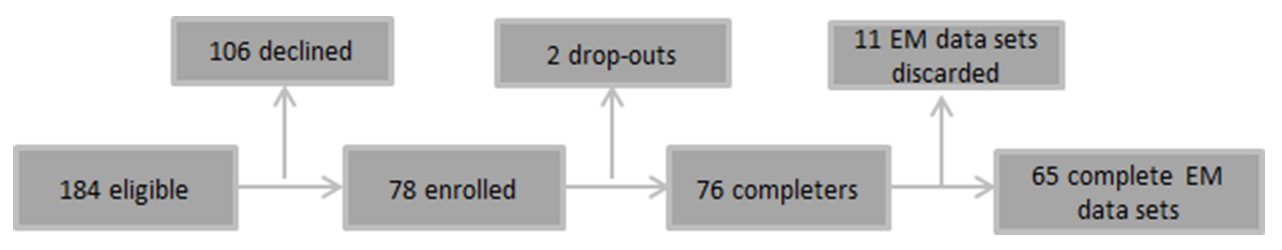

Figure 2 Flow chart for eligibility, drop-outs and data loss.

routine, and obstacles. However, the degree to which patients considered their immunosuppressant necessary for their health and survival was significantly correlated to Taking Adherence $(\tau=0.22, p=0.04)$, but not Timing Adherence ( $\pm 2 \mathrm{~h}, \pm 30 \mathrm{~min}$ ). Instead, general beliefs concerning physicians' overuse and possible harmful effects of medication showed a significant association with Timing Adherence $\pm 2 \mathrm{~h}$ ( $\tau=-.19, \mathrm{p}=0.04$ ), but not Taking Adherence or Timing Adherence $\pm 30 \mathrm{~min}$. How well the patients felt informed about their medication in case of action and usage was significantly correlated with Timing Adherence $\pm 2 \mathrm{~h}$ $(\tau=0.20, \mathrm{p}=0.05)$.

In our sample, $11 \%$ exhibited clinically relevant depressive symptoms (PHQ $\geq 10$ ). Self-efficacy, social support, attachment, and perceived health-related quality of life were comparable to an average healthy population.

Due to statistical preconditions of limited predictor count in multiple regressions, we extracted variables with sound scientific support that have repeatedly been related to $\mathrm{NA}$ in previous research. We consequently narrowed the variables down to the following: age, sex, time since last transplantation, immunosuppressive medication, depression, and perceived social support. ${ }^{65}$ For Taking Adherence we added the predictor Specific-Necessities and for Timing Adherence $\pm 2 \mathrm{~h}$ SIMS - Action and Usage since it correlated significantly with the respective outcome in our sample (Table 3 ). The regression model revealed immunosuppressive medication as a significant predictor for Taking Adherence (Table 4). The belief in the necessity of the respective immunosuppressant did no longer show a significant influence on Taking Adherence. For Timing Adherence $( \pm 2 \mathrm{~h}, \pm 30 \mathrm{~min})$, none of the variables were significant.

\section{Discussion}

This study prospectively investigated the association between a variety of potential risk factors and electronically monitored NA in renal transplant recipients. Over the study period of 3 months, adherence was relatively high with adherence rates of $99.39 \%, 98.34 \%$, and $93.34 \%$ for
Taking Adherence, Timing Adherence $\pm 2 \mathrm{~h}$, and Timing Adherence $\pm 30 \mathrm{~min}$, respectively. Despite these high prevalences, similar rates could be found in previous studies applying EM. ${ }^{22,66}$

We only found immunosuppressive medication to be associated with Taking Adherence. Patients receiving AdvagrafC (once-daily) depicted better Taking Adherence than patients receiving Prograf $($ (twice-daily). This is in line with previous research which indicates that patients with a once-daily dosage of immunosuppressive medication display higher adherence than patients with a more frequent dosing regimen. ${ }^{30-34}$ This finding also corresponds to literature investigating this phenomenon in other transplant populations. ${ }^{67,68}$ Although most research confirms our findings, in clinical practice still many patients receive immunosuppressants with a higher dosing frequency. In our sample, $38.5 \%$ still had a twice-daily dosing regimen of their immunosuppressant. The switch to a once-daily extended release of tacrolimus was found to be medically safe and more convenient for renal transplant recipients. ${ }^{32-34,69}$ In liver transplant recipients the conversion was even found to improve medical outcomes. ${ }^{70}$ Thus, efforts should be made to reduce the dosing schedule in the future. Still, it must be noted that dose omission cannot be prevented. Although it is less likely to miss a dose when on a once-daily dosing schedule, missing a once-daily dose can lead to a 24-hour interval without dose at all. ${ }^{30}$ Even though pharmacological effects of different dosing errors have not been investigated thoroughly, potential changes in clinical outcomes cannot be excluded. ${ }^{30}$ Subsequently, the effects of dosing errors and the specific needs of each patient must be considered carefully when changing the dosing frequency. ${ }^{30}$

Our data further revealed that Timing Adherence was not affected by dosing frequency, which means that a second dose is either taken on time or not at all. Except for dosing frequency, our study revealed no further associations of potential determinants with electronically monitored adherence when combining the relevant factors in a regression model. These findings are somewhat contradictory to current research. Although 
Table 2 Sociodemographic, Biomedical and Psychosocial Variables

\begin{tabular}{|c|c|c|}
\hline Sociodemographic and Psychosocial Variables & & Total sample $(\mathrm{N}=\mathbf{7 8})$ \\
\hline Age & & 55.28 ( \pm I I.52), 30-78 \\
\hline \multirow[t]{2}{*}{ Sex } & Males & 56 (71.8) \\
\hline & Females & $22(28.2)$ \\
\hline \multirow[t]{2}{*}{ Marital Status } & Married/in a relationship & $60(76.9)$ \\
\hline & Single/Widowed/Divorced & $18(23.1)$ \\
\hline \multirow[t]{3}{*}{ Employment Status } & Employed (full or part-time) & $30(38.5)$ \\
\hline & Unemployed/retired & $4 I(52.6)$ \\
\hline & No information/Other & $7(8.9)$ \\
\hline \multirow[t]{3}{*}{ Education } & Intermediate school or less $(<12$ years $)$ & $61(78.2)$ \\
\hline & High School or higher (>12 years) & $16(20.5)$ \\
\hline & No information & $\mathrm{I}(\mathrm{I} .3)$ \\
\hline \multirow[t]{3}{*}{ Migration Background ${ }^{\mathrm{a}}$} & Yes & $5(6.4)$ \\
\hline & No (German) & $72(92.3)$ \\
\hline & No information & $\mathrm{I}(\mathrm{l} .3)$ \\
\hline \multirow[t]{2}{*}{ Immunosuppressive Medication } & Advagraf@ (once daily) & $48(61.5)$ \\
\hline & Prograf@ (twice daily) & $30(38.5)$ \\
\hline Total Number of Medications & & $10.85( \pm 4.17), 3-22$ \\
\hline \multirow[t]{2}{*}{ Type of Renal Graft } & Living & $31(39.7)$ \\
\hline & Postmortem & $47(60.3)$ \\
\hline \multirow[t]{3}{*}{ Total Number of Tx } & 1 & $70(89.7)$ \\
\hline & 2 & $6(7.7)$ \\
\hline & 3 & $2(2.6)$ \\
\hline \multirow[t]{3}{*}{ Types of Organs Transplanted } & Single Kidney Transplantation & $70(89.7)$ \\
\hline & Dual Kidney Transplantation & $\mathrm{I}(\mathrm{l} .3)$ \\
\hline & Pancreas-Kidney Transplantation & $7(9.0)$ \\
\hline \multirow{7}{*}{$\begin{array}{l}\text { Time Since Last Transplantation (In Years) } \\
\text { Primary Disease }\end{array}$} & & $5.64( \pm 4.23),<1-17^{\mathrm{e}}$ \\
\hline & Glomerulonephritis & $27(34.6)$ \\
\hline & Systemic disease & $7(9.0)$ \\
\hline & Metabolic/hypertensive & $19(24.4)$ \\
\hline & Genetic & $10(12.8)$ \\
\hline & Other & $12(15.4)$ \\
\hline & Unknown & $3(3.8)$ \\
\hline \multirow[t]{8}{*}{ Frequent Comorbid Conditions ${ }^{\mathrm{b}}$} & Diabetes & $18(23.1)$ \\
\hline & Heart condition & $25(32.1)$ \\
\hline & Hypertension & $62(79.5)$ \\
\hline & Hyperuricemia & $15(19.2)$ \\
\hline & Hyperparathyroidism & $7(9)$ \\
\hline & Hyperlipidemia & $20(25.6)$ \\
\hline & Obesity & $5(6.4)$ \\
\hline & Anemia & $5(6.4)$ \\
\hline Total Number of Comorbid Conditions & & $3.32(1.75), 1-8$ \\
\hline \multirow[t]{3}{*}{ Pathological Events During Study Course } & None & 75 (96.2) \\
\hline & Rejection reactions & $2(2.6)$ \\
\hline & Acute graft failure & $\mathrm{I}(1.3)$ \\
\hline
\end{tabular}

(Continued) 
Table 2 (Continued).

\begin{tabular}{|c|c|c|}
\hline Sociodemographic and Psychosocial Variables & & Total sample $(\mathbf{N}=78)$ \\
\hline \multirow[t]{3}{*}{ Hospitalizations During Study Course } & 0 & 67 (85.9) \\
\hline & 1 & $8(10.3)$ \\
\hline & 2 & $3(3.8)$ \\
\hline Depression & & 4.74 ( \pm 4.12$), 0-17(0-27)$ \\
\hline \multirow[t]{2}{*}{ Depression Dichotomous $(\geq 10)$} & Low & $68(88.31)$ \\
\hline & High & $9(11.69)$ \\
\hline Perceived Social Support & & $4.33( \pm 0.85), 1.29-5.0(1-5)$ \\
\hline \multirow[t]{4}{*}{ Perceived Health-Related Quality of Life } & Physical Health & 73.38 ( \pm 16.99$), 36-100(0-100)$ \\
\hline & Psychological Health & 74.30 ( \pm 17.28$), 8-100(0-100)$ \\
\hline & Social relationships & $68.10( \pm 21.60), 0-100(0-100)$ \\
\hline & Environment & $81.53( \pm 14.35), 38-100(0-100)$ \\
\hline Self-Efficacy & & $29.78( \pm 5.11), 17-40(10-40)$ \\
\hline \multirow[t]{4}{*}{ Attachment $^{c}$} & Fear of separation & $2.48( \pm 0.62), 1.40-4.80(I-5)$ \\
\hline & Fear of closeness Lack of trust & $2.11( \pm 0.68), 1.00-4.00(1-5)$ \\
\hline & Desire for independence & $1.92( \pm 0.72), 1.00-4.86(1-5)$ \\
\hline & & $3.70( \pm 0.78), 1.00-5.00(I-5)$ \\
\hline $\begin{array}{l}\text { Subjective Experiences and Attitudes Towards } \\
\text { Immunosuppressive Medication }\end{array}$ & & 13.56 ( \pm 5.50$), 4-23(4-33)$ \\
\hline \multirow[t]{5}{*}{ Emotional Responses After Organ Transplantation ${ }^{d}$} & Guilt & $2.56( \pm 0.41), 1.67-3.5(I-5)$ \\
\hline & Worry & $2.77( \pm 0.85), 1.0-4.6(1-5)$ \\
\hline & Disclosure & $4.48( \pm 0.82), 1.67-5.0(I-5)$ \\
\hline & Adherence & $4.52( \pm 0.62), 2.0-5.0(1-5)$ \\
\hline & Responsibility & $3.42( \pm 0.97), 1.0-5.0(I-5)$ \\
\hline Satisfaction with Information About Immunosuppressive & Total & $12.96( \pm 3.84), 3-17(0-17)$ \\
\hline \multirow[t]{2}{*}{ Medication } & Action and usage & $7.70( \pm 1.69), 2-9(0-9)$ \\
\hline & Potential problems of medication & $5.26( \pm 2.74), 0-8(0-8)$ \\
\hline \multirow[t]{6}{*}{ Perceptions of and Beliefs About Medications } & General - Total & 17.19 ( \pm 5.67$), 8-29(8-40)$ \\
\hline & General - Overuse & 7.49 ( \pm 2.90$), 3-15(3-15)$ \\
\hline & General - Harm & $9.71( \pm 3.41), 5-18(5-25)$ \\
\hline & Specific - Total & $33.10( \pm 3.79), 25-43(10-50)$ \\
\hline & Specific - Necessities & $23.05( \pm 2.60), 15-25(5-25)$ \\
\hline & Specific - Concerns & $10.04( \pm 3.80), 5-20(5-25)$ \\
\hline \multirow[t]{3}{*}{ Support When Taking Medication } & Yes & $8(10.3)$ \\
\hline & No & $69(88.5)$ \\
\hline & No information & I ( 1.3$)$ \\
\hline \multirow[t]{3}{*}{ Use of Reminders } & Yes & $27(34.6)$ \\
\hline & No & $50(64.1)$ \\
\hline & No information & I (1.3) \\
\hline \multirow[t]{3}{*}{ Intake is Linked to Daily Routine } & Yes & $20(25.6)$ \\
\hline & No & $57(73.1)$ \\
\hline & No information & I (1.3) \\
\hline
\end{tabular}


Table 2 (Continued).

\begin{tabular}{|c|c|c|}
\hline Sociodemographic and Psychosocial Variables & & Total sample $(\mathbf{N}=\mathbf{7 8})$ \\
\hline \multirow[t]{3}{*}{ Obstacles } & Yes & $23(29.5)$ \\
\hline & No & $54(69.2)$ \\
\hline & No information & I ( $(1.3)$ \\
\hline Taking Adherence* & & $99.39( \pm 1.75), 86.92-100$ \\
\hline Timing Adherence $\pm 2 \mathrm{~h}^{*}$ & & $98.34( \pm 3.16), 77.57-100$ \\
\hline Timing Adherence $\pm 30 \mathrm{~min}^{*}$ & & 93.34 ( \pm 11.37$), 21.5-100$ \\
\hline
\end{tabular}

Notes: Except as indicated, categorical data are presented as count (percentage), continuous data are presented as mean ( \pm standard deviation), range (total range possible). a Migration background is defined as either immigrated personally or having at least one parent who has immigrated, 'Several conditions per patient possible ${ }^{\mathrm{C}} \mathrm{German}$ factorization, ${ }^{55}$ German interpretation of TxEQ, ${ }^{58} \mathrm{e}<1$ includes patients $>6$ months to $<1$ year. $*_{n}=65$.

we could not find an association between depression and NA, intentionality of NA must be taken into account. Griva et $\mathrm{al}^{15}$ found that depression was only related to intentional NA, but not to non-intentional NA like forgetfulness. Whilst we did not examine the reasons for omitted intakes, it is likely that patients did not act deliberately. The absence of an association between depression and NA can also be seen in other studies. ${ }^{17,24}$

The lack of further associations between NA and other patient-related factors in our sample could be explained by our highly adherent population. Influential factors on adherence behavior could subsequently be different for less adherent patients. A possible reason could also be the low prevalence of depression in our cohort (11.69\%), compared to other study populations depicting prevalence rates between $13.2 \%$ and $60 \% .{ }^{15,18,28,71}$ At the same time, protective factors such as self-efficacy, social support, and quality of life, as well as satisfaction with information were average to high and comparable to an average healthy population.

In sum, this field of research still displays a high ambiguity in results since associations between adherence and possible influential factors are not straightforward. ${ }^{28,72}$ Whilst most research was able to link NA to lower social support, some could not. ${ }^{65,73}$ The same heterogeneity applies to age, ${ }^{23} \mathrm{sex},{ }^{4,18}$ time since transplantation, ${ }^{28}$ and a variety of other psychosocial factors. ${ }^{65}$ Further research is necessary in order to gain more consistent results. Especially, a standardization of measurement methods should be pursued in order to attain a better comparability across studies.

\section{Limitations}

One limitation of your study is our uniformly adherent sample with little variation in electronically monitored data, which makes inferences challenging. In this context, a possible responder bias towards more adherent patients cannot be excluded.

Also, this study was restricted to patient-related factors, whereas health system and health care provider factors might also play a key role in the development of adherent behavior. $^{2,11,74}$ This could also explain why our statistical model on taking adherence only explained a variance of $16 \%$, which limits generalizability. Especially due to our limited sample size, results should be interpreted with caution.

A further constraint of this study is that potential electronic measurement errors might have occurred. ${ }^{41-45}$ Especially, a possible intervention effect caused by the use of electronics could subsequently bias the interpretation of our results. ${ }^{42,44,47}$

It is also possible that patients' diaries were incomplete and thus electronic data were biased. Especially since a more thorough diary keeping could be associated with higher adherence ${ }^{64}$ and thus increasing the gap between adherent and less adherent patients.

\section{Conclusion}

In highly adherent populations, only a few factors can be altered to improve adherence. However, changing the immunosuppressive regimen from twice-daily to oncedaily could be an option for optimizing Taking Adherence. Risk factors for NA could be different for less adherent patients; therefore, our results should be replicated in a less adherent and bigger population of renal transplant recipients. Future studies should also include factors from the meso- and macro-level, such as health care system and health care provider factors ${ }^{2,11,74,75}$ in order to gain a more thorough picture of NA. Subsequent projects should also 
Table 3 Associations Between Psychosocial Variables and Electronically Monitored Adherence

\begin{tabular}{|c|c|c|c|c|}
\hline $\begin{array}{l}\text { Sociodemographic and Psychosocial } \\
\text { Construct }\end{array}$ & & $\begin{array}{l}\text { Taking Adherence } \\
\text { Total }(n=65)\end{array}$ & $\begin{array}{l}\text { Timing Adherence } \\
\pm 2 h(n=65)\end{array}$ & $\begin{array}{l}\text { Timing Adherence } \\
\pm 30 \mathrm{~min}(\mathrm{n}=65)\end{array}$ \\
\hline Age & & $\tau=-0.05, p=0.61$ & $\tau=-0.02, p=0.85$ & $\tau=-0.02, p=0.81$ \\
\hline Sex & & $U=432.00, p=0.93$ & $U=385.50, p=0.43$ & $U=381.00, p=0.42$ \\
\hline Marital Status & $\begin{array}{l}\text { Single } \\
\text { In a relationship }\end{array}$ & $U=363.00, p=0.82$ & $U=303.500, p=0.24$ & $U=362.50, p=0.85$ \\
\hline Employment Status & $\begin{array}{l}\text { Employed (full or part- } \\
\text { time) } \\
\text { Unemployed/retired }\end{array}$ & $U=358.50, p=0.45$ & $U=383.00, p=0.83$ & $U=390.00, p=0.92$ \\
\hline Education & $\begin{array}{l}\text { Intermediate school or } \\
\text { less (< 12years) } \\
\text { High School or higher } \\
\text { (>12 years) }\end{array}$ & $U=233.50, p=0.09$ & $U=300.00, p=0.83$ & $U=261.50, p=0.38$ \\
\hline Migration Background & $\begin{array}{l}\text { Yes } \\
\text { No (German) }\end{array}$ & Not computable & Not computable & Not computable \\
\hline Immunosuppressive Medication & $\begin{array}{l}\text { Advagraf@ (once daily) } \\
\text { Prograf@ (twice daily) }\end{array}$ & $\begin{array}{l}U=346.50 * \\
p=0.01\end{array}$ & $U=380.00, p=0.09$ & $U=381.50, p=0.12$ \\
\hline Total Number of Medications & & $\tau=0.17, p=0.08$ & $\tau=0.10, p=0.28$ & $\tau=0.05, p=0.60$ \\
\hline Type of Renal Graft & $\begin{array}{l}\text { Living } \\
\text { Postmortem }\end{array}$ & $U=462.50, p=0.73$ & $U=388.00, p=0.17$ & $U=358.00, p=0.09$ \\
\hline Time Since Last Transplantation & & $\tau=-0.07, p=0.51$ & $\tau=-.03, p=77$ & $\tau=-.06, p=0.50$ \\
\hline Depression & & $\tau=0.05, p=0.60$ & $\tau=0.02, p=0.83$ & $\tau=0.12, p=0.19$ \\
\hline Depression Dichotomous $(\geq 10)$ & & $U=161.50, p=0.73$ & $U=161.00, p=0.73$ & $U=149.00, p=0.54$ \\
\hline Perceived Social Support & & $\tau=-0.16, p=0.12$ & $\tau=0.01, p=0.94$ & $\tau=0.03, p=0.74$ \\
\hline Perceived Health-Related Quality of Life & $\begin{array}{l}\text { Physical Health } \\
\text { Psychological Health } \\
\text { Social relationships } \\
\text { Environment }\end{array}$ & $\begin{aligned} \tau & =-0.03, p=0.75 \\
\tau & =0.01, p=0.95 \\
\tau & =-0.10, p=0.34 \\
\tau & =0.12, p=0.29\end{aligned}$ & $\begin{aligned} \tau & =-0.07, p=0.44 \\
\tau & =0.07, p=0.48 \\
\tau & =0.04, p=0.70 \\
\tau & =0.08, p=0.39\end{aligned}$ & $\begin{aligned} \tau & =-0.14, \mathrm{P}=0.1 \mathrm{I} \\
\tau & =0.01, \mathrm{p}=0.94 \\
\tau & =-0.03, \mathrm{P}=0.73 \\
\tau & =-0.06, \mathrm{p}=0.54\end{aligned}$ \\
\hline Self-Efficacy & & $\tau=-0.09, p=0.38$ & $\tau=-0.02, p=0.82$ & $\tau=0.02, p=0.84$ \\
\hline Attachment & $\begin{array}{l}\text { Fear of separation } \\
\text { Fear of closeness } \\
\text { Lack of trust } \\
\text { Desire for } \\
\text { independence }\end{array}$ & $\begin{aligned} \tau & =0.04, p=0.67 \\
\tau & =-0.08, p=0.30 \\
\tau & =0.10, p=0.30 \\
\tau & =-0.09, p=0.39\end{aligned}$ & $\begin{aligned} \tau & =0.09, \mathrm{p}=0.36 \\
\tau & =-0.14, \mathrm{p}=0.14 \\
\tau & =-0.00, \mathrm{p}=0.99 \\
\tau & =-0.12, \mathrm{p}=0.26\end{aligned}$ & $\begin{aligned} \tau & =0.13, \mathrm{p}=0.14 \\
\tau & =-0.14, \mathrm{P}=0.11 \\
\tau & =-0.06, \mathrm{P}=0.48 \\
\tau & =-0.09, \mathrm{p}=0.34\end{aligned}$ \\
\hline $\begin{array}{l}\text { Subjective Experiences and Attitudes Towards } \\
\text { Immunosuppressive Medication }\end{array}$ & & $\tau=0.10, p=0.32$ & $\tau=0.13, p=0.16$ & $\tau=0.11, p=0.23$ \\
\hline $\begin{array}{l}\text { Emotional Responses After Organ } \\
\text { Transplantation }\end{array}$ & $\begin{array}{l}\text { Guilt } \\
\text { Worry } \\
\text { Disclosure } \\
\text { Adherence } \\
\text { Responsibility }\end{array}$ & $\begin{aligned} \tau & =-0.09, \mathrm{p}=0.39 \\
\tau & =-0.01, \mathrm{P}=0.93 \\
\tau & =0.10, \mathrm{p}=0.37 \\
\tau & =\mathbf{0 . 3 0} \text { **, } \mathbf{p}<\mathbf{0 . 0 1} \\
\tau & =0.06, \mathrm{p}=0.53\end{aligned}$ & $\begin{aligned} \tau & =-.015, p=0.12 \\
\tau & =-0.01, p=0.89 \\
\tau & =0.01, p=0.95 \\
\tau & =\mathbf{0} .36 * *, p<0.01 \\
\tau & =0.00, p=0.99\end{aligned}$ & $\begin{aligned} \tau & =-0.10, \mathrm{p}=0.28 \\
\tau & =-0.06, \mathrm{p}=0.49 \\
\tau & =0.01, \mathrm{p}=0.95 \\
\tau & =\mathbf{0 . 3 9} * *, \mathrm{p}<\mathbf{0 . 0 1} \\
\tau & =-0.06, \mathrm{p}=0.52\end{aligned}$ \\
\hline
\end{tabular}

(Continued) 
Table 3 (Continued).

\begin{tabular}{|c|c|c|c|c|}
\hline $\begin{array}{l}\text { Sociodemographic and Psychosocial } \\
\text { Construct }\end{array}$ & & $\begin{array}{l}\text { Taking Adherence } \\
\text { Total }(n=65)\end{array}$ & $\begin{array}{l}\text { Timing Adherence } \\
\pm 2 h(n=65)\end{array}$ & $\begin{array}{l}\text { Timing Adherence } \\
\pm 30 \mathrm{~min}(\mathrm{n}=65)\end{array}$ \\
\hline $\begin{array}{l}\text { Satisfaction with Information About } \\
\text { Immunosuppressive Medication }\end{array}$ & $\begin{array}{l}\text { Total } \\
\text { Action and usage } \\
\text { Potential problems of } \\
\text { medication }\end{array}$ & $\begin{aligned} \tau & =0.08, \mathrm{P}=0.44 \\
\tau & =0.12, \mathrm{P}=0.27 \\
\tau & =0.04, \mathrm{P}=0.68\end{aligned}$ & $\begin{aligned} \tau & =0.15, \mathrm{p}=0.12 \\
\tau & =\mathbf{0 . 2 0 *}, \mathrm{p}=\mathbf{0 . 0 5} \\
\tau & =0.11, \mathrm{p}=0.25\end{aligned}$ & $\begin{aligned} \tau & =0.08, \mathrm{p}=0.36 \\
\tau & =0.10, \mathrm{p}=0.30 \\
\tau & =0.07, \mathrm{p}=0.47\end{aligned}$ \\
\hline Perceptions of and Beliefs About Medications & $\begin{array}{l}\text { General - Total } \\
\text { General - Overuse } \\
\text { General - Harm } \\
\text { Specific - Total } \\
\text { Specific - Necessities } \\
\text { Specific - Concerns }\end{array}$ & $\begin{aligned} \tau & =-0.12, \mathrm{p}=0.22 \\
\tau & =-0.13, \mathrm{p}=0.19 \\
\tau & =-0.07, \mathrm{p}=0.5 \mathrm{I} \\
\tau & =0.12, \mathrm{p}=0.21 \\
\tau & =\mathbf{0 . 2 2 *}, \mathrm{p}=\mathbf{0 . 0 4} \\
\tau & =0.02, \mathrm{p}=0.88\end{aligned}$ & $\begin{array}{l}\tau=-0.19 *, p=0.04 \\
\tau=-0.17, p=0.07 \\
\tau=-0.17, p=0.08 \\
\tau=-0.03, p=0.76 \\
\tau=0.04, p=0.68 \\
\tau=-0.04, p=0.67\end{array}$ & $\begin{aligned} \tau & =-0.14, p=0.12 \\
\tau & =-0.15, p=0.11 \\
\tau & =-0.10, p=0.29 \\
\tau & =-0.05, p=0.58 \\
\tau & =0.08, p=0.40 \\
\tau & =-0.10, p=0.24\end{aligned}$ \\
\hline Support When Taking Medication & & Not computable & Not computable & Not computable \\
\hline Use of Reminders & & $U=418.00, p=0.69$ & $U=421.00, p=0.77$ & $U=403.50, p=0.60$ \\
\hline Intake is Linked to Daily Routine & & $\begin{array}{l}U=383.00, p= \\
0.985\end{array}$ & $U=344.00, p=0.52$ & $U=380.00, p=0.95$ \\
\hline Obstacles & & $U=282.00, p=0.09$ & $U=258.00, p=0.07$ & $U=293.00, p=0.24$ \\
\hline
\end{tabular}

Notes: For correlations, we depicted Kendall's tau; for dichotomous variables, we used Mann-Whitney U-Tests. Significant results are depicted in bold: **p $\leq 0.01$, *p $\leq 0.05$.

Table 4 Multiple Regression Analyses

\begin{tabular}{|c|c|c|c|c|c|}
\hline Dependent Variable & Parameter & B & $95 \% \mathrm{Cl}$ & $\mathbf{p}$ & $\mathbf{R 2}$ \\
\hline Taking Adherence & $\begin{array}{l}\text { Constant } \\
\text { Age } \\
\text { Sex } \\
\text { Immunosuppressive Medication } \\
\text { Perceived social support } \\
\text { Depression } \\
\text { Last transplantation } \\
\text { Specific - Necessities }\end{array}$ & $\begin{array}{l}100.84 \\
-0.01 \\
0.17 \\
-0.49 \\
-0.18 \\
0.00 \\
-0.00 \\
0.01\end{array}$ & $\begin{array}{l}97.68,103.28 \\
-03,0.01 \\
-0.24,0.63 \\
-0.87,0.001 \\
-0.57,0.25 \\
-0.08,0.10 \\
-0.08,0.10 \\
-0.05,0.08\end{array}$ & $\begin{array}{l}<0.0 I^{*} \\
0.34 \\
0.46 \\
0.04^{*} \\
0.44 \\
0.99 \\
0.86 \\
0.74\end{array}$ & 0.16 \\
\hline Timing Adherence $\pm 2 \mathrm{~h}$ & $\begin{array}{l}\text { Constant } \\
\text { Age } \\
\text { Sex } \\
\text { Immunosuppressive Medication } \\
\text { Perceived social support } \\
\text { Depression } \\
\text { Last transplantation } \\
\text { General - Total } \\
\text { SIMS - Action and Usage }\end{array}$ & $\begin{array}{l}98.28 \\
-0.01 \\
-0.11 \\
-0.21 \\
0.02 \\
0.07 \\
-0.02 \\
-0.07 \\
0.24\end{array}$ & $\begin{array}{l}90.17,103.82 \\
-0.06,0.04 \\
-1.23,1.13 \\
-1.06,0.81 \\
-0.92,1.19 \\
-0.14,0.31 \\
-0.15,0.10 \\
-0.17,0.63 \\
-0.04,0.63\end{array}$ & $\begin{array}{l}<0.01 * \\
0.67 \\
0.86 \\
0.65 \\
0.98 \\
0.55 \\
0.78 \\
0.16 \\
0.14\end{array}$ & 0.14 \\
\hline Timing Adherence \pm 30 min & $\begin{array}{l}\text { Constant } \\
\text { Age } \\
\text { Sex } \\
\text { Immunosuppressive Medication } \\
\text { Perceived social support } \\
\text { Depression } \\
\text { Last transplantation }\end{array}$ & $\begin{array}{l}89.27 \\
-0.07 \\
1.75 \\
-1.16 \\
1.43 \\
0.59 \\
-0.04\end{array}$ & $\begin{array}{l}69.06,104.36 \\
-0.27,0.09 \\
-2.36,6.30 \\
-4.64,2.92 \\
-1.70,5.24 \\
-0.04,1.36 \\
-0.45,0.41\end{array}$ & $\begin{array}{l}<01 * \\
0.40 \\
0.40 \\
0.52 \\
0.42 \\
0.11 \\
0.83\end{array}$ & 0.09 \\
\hline
\end{tabular}

Notes: Advagraf $=0$, Prograf $=1$; estimates are based on 10,000 Bootstrap-samples. Significant results are depicted in bold: $*_{p}<0.05$. 
investigate the characteristics of this sample more profoundly in order to identify possible reasons for this highly adherent behavior.

\section{Abbreviations}

NA, non-adherence; EM, electronic monitoring; IS levels, immunosuppressive levels.

\section{Data Sharing Statement}

The data supporting our findings can be requested from Dipl.-Psych. Marietta Lieb (marietta.lieb@uk-erlangen.de) and Prof. Yesim Erim (yesim.erim@uk-erlangen.de).

\section{Ethics Approval and Informed Consent}

Before study participation, written informed consent was given by all participants. Institutional ethics board approval was obtained from the Clinical Ethics Committee of the University Hospital Erlangen (Friedrich-AlexanderUniversity, Erlangen-Nürnberg, FAU). All organs were donated voluntarily with written informed consent. Organ transplantation was conducted in accordance with the Declaration of Istanbul.

\section{Acknowledgments}

We like to thank the staff of the nephrologic outpatient clinic and all patients who participated in our study. The present work was performed in (partial) fulfillment of the requirements for obtaining the degree "Dr. rer. biol. hum.".

\section{Author Contributions}

ML designed and performed the study, collected and analyzed the data, and drafted the manuscript. MS enabled and supported the conduction of the study. YE supervised the conceptualization of the study and conduction of the study. All authors (ML, MS, YE) contributed to data analysis, drafting or revising the article, gave final approval of the version to be published, and agree to be accountable for all aspects of the work.

\section{Funding}

No funding was obtained for the conduction of this project.

\section{Disclosure}

The authors declare no conflicts of interest in this work.

\section{References}

1. Vrijens B, De Geest S, Hughes DA, et al. A new taxonomy for describing and defining adherence to medications. $\mathrm{Br} \mathrm{J}$ Clin Pharmacol. 2012;73(5):691-705. doi:10.1111/j.1365-2125.2012.04 167.x

2. Denhaerynck K, Dobbels F, Cleemput I, et al. Prevalence, consequences, and determinants of nonadherence in adult renal transplant patients: a literature review. Transpl Int. 2005;18(10):1121-1133. doi:10.1111/j.1432-2277.2005.00176.x

3. Scheel J, Reber S, Stoessel L, et al. Patient-reported non-adherence and immunosuppressant trough levels are associated with rejection after renal transplantation. BMC Nephrol. 2017;18(1):107. doi:10.1186/s12882-017-0517-6

4. Pinsky BW, Takemoto SK, Lentine KL, et al. Transplant outcomes and economic costs associated with patient noncompliance to immunosuppression. Am J Transplant. 2009;9(11):2597-2606. doi:10.1111/j.1600-6143.2009.02798.x

5. De Geest S, Abraham I, Moons P, et al. Late acute rejection and subclinical noncompliance with cyclosporine therapy in heart transplant recipients. J Heart Lung Transplant. 1998;17(9):854-863.

6. Dew MA, DiMartini AF, De Vito Dabbs A, et al. Rates and risk factors for nonadherence to the medical regimen after adult solid organ transplantation. Transplantation. 2007;83(7):858-873. doi:10. 1097/01.tp.0000258599.65257.a6

7. Zhu Y, Zhou Y, Zhang L, et al. Efficacy of interventions for adherence to the immunosuppressive therapy in kidney transplant recipients: a meta-analysis and systematic review. J Investig Med. 2017;65 (7):1049-1056. doi:10.1136/jim-2016-000265

8. Foster BJ, Pai A, Zelikovsky N, et al. A randomized trial of a multicomponent intervention to promote medication adherence: the teen adherence in kidney transplant effectiveness of intervention trial (TAKE-IT). Am J Kidney Dis. 2018;72(1):30-41. doi:10.1053/j. ajkd.2017.12.012

9. Russell CL, Hathaway D, Remy LM, et al. Improving medication adherence and outcomes in adult kidney transplant patients using a personal systems approach: systemCHANGE results of the MAGIC randomized clinical trial. Am $J$ Transplant. 2020;20 (1):125-136. doi:10.1111/ajt.15528

10. Low JK, Williams A, Manias E, et al. Interventions to improve medication adherence in adult kidney transplant recipients: a systematic review. Nephrol Dial Transplant. 2014;30(5):752-761.

11. Nevins TE, Nickerson PW, Dew MA. Understanding medication nonadherence after kidney transplant. J Am Soc Nephrol. 2017;28 (8):2290-2301. doi:10.1681/ASN.2017020216

12. Rosenstock IM, Strecher VJ, Becker MH. Social learning theory and the health belief model. Health Educ O. 1988;15(2):175-183. doi:10.1177/109019818801500203

13. Reber S, Morawa E, Stossel L, et al. Prevalence and modifiable determinants of non-adherence in adult kidney transplant recipients in a German sample. Z Psychosom Med Psychother. 2016;62 (3):270-283. doi:10.13109/zptm.2016.62.3.270

14. Chisholm-Burns M, Pinsky B, Parker G, et al. Factors related to immunosuppressant medication adherence in renal transplant recipients. Clin Transplant. 2012;26(5):706-713. doi:10.1111/ j.1399-0012.2011.01589.x

15. Griva K, Davenport A, Harrison M, et al. Non-adherence to immunosuppressive medications in kidney transplantation: intent vs. forgetfulness and clinical markers of medication intake. Ann Behav Med. 2012;44(1):85-93. doi:10.1007/s12160-012-9359-4

16. Schmid-Mohler G, Thut MP, Wuthrich RP, et al. Non-adherence to immunosuppressive medication in renal transplant recipients within the scope of the integrative model of behavioral prediction: a cross-sectional study. Clin Transplant. 2010;24(2):213-222. doi:10.1111/j.1399-0012.2009.01056.x 
17. Weng FL, Chandwani S, Kurtyka KM, et al. Prevalence and correlates of medication non-adherence among kidney transplant recipients more than 6 months post-transplant: a cross-sectional study. BMC Nephrol. 2013;14:261. doi:10.1186/1471-2369-14-261

18. Pabst S, Bertram A, Zimmermann T, et al. Physician reported adherence to immunosuppressants in renal transplant patients: prevalence, agreement, and correlates. J Psychosom Res. 2015;79(5):364-371. doi:10.1016/j.jpsychores.2015.09.001

19. DiMatteo MR, Lepper HS, Croghan TW. Depression is a risk factor for noncompliance with medical treatment: meta-analysis of the effects of anxiety and depression on patient adherence. Arch Intern Med. 2000;160(14):2101-2107. doi:10.1001/archinte.160.14.2101

20. Jindal RM, Neff RT, Abbott KC, et al. Association between depression and nonadherence in recipients of kidney transplants: analysis of the United States renal data system. Transplant Proc. 2009;41 (9):3662-3666. doi:10.1016/j.transproceed.2009.06.187

21. Prihodova L, Nagyova I, Rosenberger J, et al. Adherence in patients in the first year after kidney transplantation and its impact on graft loss and mortality: a cross-sectional and prospective study. $J A d v$ Nurs. 2014;70(12):2871-2883. doi:10.1111/jan.12447

22. Denhaerynck K, Steiger J, Bock A, et al. Prevalence and risk factors of non-adherence with immunosuppressive medication in kidney transplant patients. Am J Transplant. 2007;7(1):108-116. doi:10. 1111/j.1600-6143.2006.01611.x

23. Liu J, Liu S, Yan J, et al. Adherence to immunosuppressive medication in renal transplant recipients from follow-up outpatient in China: association of 2 different measurement methods. Clin Ther. 2015;37 (11):2572-2580. doi:10.1016/j.clinthera.2015.09.014

24. Russell CL, Ashbaugh C, Peace L, et al. Time-in-a-bottle (TIAB): a longitudinal, correlational study of patterns, potential predictors, and outcomes of immunosuppressive medication adherence in adult kidney transplant recipients. Clin Transplant. 2013;27(5):E580-590. doi:10.1111/ctr.12203

25. Calia R, Lai C, Aceto P, et al. Emotional self-efficacy and alexithymia may affect compliance, renal function and quality of life in kidney transplant recipients: results from a preliminary cross-sectional study. Physiol Behav. 2015;142:152-154. doi:10.1016/j.physbeh.2015.02.018

26. Silva AN, Moratelli L, Tavares PL, et al. Self-efficacy beliefs, locus of control, religiosity and non-adherence to immunosuppressive medications in kidney transplant patients. Nephrology (Carlton). 2016;21 (11):938-943. doi:10.1111/nep.12695

27. Calia R, Lai C, Aceto P, et al. Attachment style predict compliance, quality of life and renal function in adult patients after kidney transplant: preliminary results. Ren Fail. 2015;37(4):678-680. doi:10.3109/0886022X.2015.1010989

28. Scheel JF, Schieber K, Reber S, et al. Psychosocial variables associated with immunosuppressive medication non-adherence after renal transplantation. Front Psychiatry. 2018;9:23. doi:10.3389/fpsyt. 2018.00023

29. Chisholm-Burns MA, Spivey CA, Wilks SE. Social support and immunosuppressant therapy adherence among adult renal transplant recipients. Clin Transplant. 2010;24(3):312-320. doi:10.1111/j.13990012.2009.01060.x

30. Kuypers DR, Peeters PC, Sennesael JJ, et al. Improved adherence to tacrolimus once-daily formulation in renal recipients: a randomized controlled trial using electronic monitoring. Transplantation. 2013;95 (2):333-340. doi:10.1097/TP.0b013e3182725532

31. Weng FL, Israni AK, Joffe MM, et al. Race and electronically measured adherence to immunosuppressive medications after deceased donor renal transplantation. J Am Soc Nephrol. 2005;16 (6):1839-1848. doi:10.1681/ASN.2004121059

32. Nakamura Y, Hama K, Katayama H, et al. Safety and efficacy of conversion from twice-daily tacrolimus (prograf) to once-daily prolonged-release tacrolimus (graceptor) in stable kidney transplant recipients. Transplant Proc. 2012;44(1):124-127. doi:10.1016/j. transproceed.2011.11.051
33. Hatakeyama S, Fujita T, Yoneyama T, et al. A switch from conventional twice-daily tacrolimus to once-daily extended-release tacrolimus in stable kidney transplant recipients. Transplant Proc. 2012;44 (1):121-123. doi:10.1016/j.transproceed.2011.11.022

34. Guirado L, Cantarell C, Franco A, et al. Efficacy and safety of conversion from twice-daily to once-daily tacrolimus in a large cohort of stable kidney transplant recipients. Am J Transplant. 2011;11(9):1965-1971. doi:10.1111/j.1600-6143.2011.03571.x

35. Denhaerynck K, Schmid-Mohler G, Kiss A, et al. Differences in medication adherence between living and deceased donor kidney transplant patients. Int J Organ Transplant Med. 2014;5(1):7-14.

36. Massey EK, Tielen M, Laging M, et al. The role of goal cognitions, illness perceptions and treatment beliefs in self-reported adherence after kidney transplantation: a cohort study. J Psychosom Res. 2013;75(3):229-234. doi:10.1016/j.jpsychores.2013.07.006

37. Foster BJ, Pai ALH. Adherence in adolescent and young adult kidney transplant recipients. Open Urol Nephrol J. 2014;7:133-143. doi:10.2174/1874303X01407010133

38. Osterberg L, Blaschke T. Adherence to medication. $N$ Engl J Med. 2005;353(5):487-497. doi:10.1056/NEJMra050100

39. Reese PP, Bloom RD, Trofe-Clark J, et al. Automated reminders and physician notification to promote immunosuppression adherence among kidney transplant recipients: a randomized trial. $\mathrm{Am}$ J Kidney Dis. 2017;69(3):400-409. doi:10.1053/j.ajkd.2016.10.017

40. Russell CL, Moore S, Hathaway D, et al. MAGIC study: aims, design and methods using systemCHANGE to improve immunosuppressive medication adherence in adult kidney transplant recipients. $B M C$ Nephrol. 2016;17(1):84. doi:10.1186/s12882-016-0285-8

41. Schäfer-Keller P, Steiger J, Bock A, et al. Diagnostic accuracy of measurement methods to assess non-adherence to immunosuppressive drugs in kidney transplant recipients. Am J Transplant. 2008;8 (3):616-626. doi:10.1111/j.1600-6143.2007.02127.x

42. Denhaerynck K, Schafer-Keller P, Young J, et al. Examining assumptions regarding valid electronic monitoring of medication therapy: development of a validation framework and its application on a European sample of kidney transplant patients. BMC Med Res Methodol. 2008;8:5. doi:10.1186/1471-2288-8-5

43. De Bleser L, De Geest S, Vandenbroeck S, et al. How accurate are electronic monitoring devices? A laboratory study testing two devices to measure medication adherence. Sensors (Basel). 2010;10:1652-1660. doi:10.3390/s100301652

44. Deschamps AE, Van Wijngaerden E, Denhaerynck K, et al. Use of electronic monitoring induces a 40-day intervention effect in HIV patients. $J$ Acquir Immune Defic Syndr. 2006;43(2):247-248. doi:10.1097/01.qai.0000246034.86135.89

45. Riekert KA, Rand CS. Electronic monitoring of medication adherence: when is high-tech best? J Clin Psychol Med Settings. 2002;8 (1):25-34. doi:10.1023/A:1014131928789

46. Dobbels F, Berben L, De Geest S, et al. The psychometric properties and practicability of self-report instruments to identify medication nonadherence in adult transplant patients: a systematic review. Transplantation. 2010;90(2):205-219. doi:10.1097/TP.0b013e3181e $346 \mathrm{~cd}$

47. Lieb M, Hepp T, Schiffer M, et al. Accuracy and concordance of measurement methods to assess non-adherence after renal transplantation - a prospective study. BMC Nephrol. 2020;21(1):114. doi:10.1186/s12882-020-01781-1

48. De Geest S, Zullig LL, Dunbar-Jacob J, et al. ESPACOMP medication adherence reporting guideline (EMERGE). Ann Intern Med. 2018;169(1):30-35. doi:10.7326/M18-0543

49. Löwe B, Spitzer R, Zipfel S, et al. Gesundheitsfragebogen für Patienten (PHQ-D). Komplettversion und Kurzform. Testmappe mit Manual, Fragebögen, Schablonen. Karlsruhe: Pfizer; 2002.

50. Kroenke K, Spitzer RL, Williams JB. The PHQ-9: validity of a brief depression severity measure. J Gen Intern Med. 2001;16(9):606-613. doi:10.1046/j.1525-1497.2001.016009606.x 
51. Fydrich T, Geyer M, Hessel A, et al. Fragebogen zur Sozialen Unterstützung (F-SozU): normierung an einer repräsentativen Stichprobe. Diagnostica. 1999;45:212-216. doi:10.1026//00121924.45.4.212

52. Angermeyer C, Kilian R, Matschinger H. Deutschsprachige Version der WHO Instrumente zur Erfassung von Lebensqualität WHOQOL100 und WHOQOL-BREFM. Z Med Psychol. 2002;11:44-48.

53. Schwarzer R, Jerusalem M. Generalized self-efficacy scale. In: Weinman J, Wright S, Johston M, editors. Measures in Health Psychology: A User's Portfolio. Causal and Control Beliefs, Windsor. England: Nfer-Nelson; 1995:35-37.

54. Schwarzer R, Jerusalem M. Skalen zur Erfassung von Lehrer- und Schülermerkmalen: Dokumentation der psychometrischen Verfahren im Rahmen der Wissenschaftlichen Begleitung des Modellversuchs Selbstwirksame Schulen. Berlin: Freie Universität Berlin; 1999.

55. Steffanowski M, Oppl J, Meyerberg J, et al. Psychometrische Überprüfung einer deutschsprachigen Version des Relationship Scales Questionnaire (RSQ). In: Bassler M, editor. Störungsspezifische Therapieansätze - Konzepte und Ergebnisse, Gießen. 2001.

56. Griffin DW, Bartholomew K. The metaphysics of measurement: the case of adult attachment. In: Bartholomew K, Perlman D, editors. Attachment Processes in Adulthood. Advances in Personal Relationships. Jessica Kingsley; 1994:17.

57. Goetzmann L, Klaghofer R, Spindler A, et al. Die "MedikamentenErfahrungs-Skala für Immunsuppressiva" (MESI) - erste Ergebnisse zu einem neuen Screeninginstrument in der Transplantationsmedizin. [The "Medication experience scale for immunosuppressants" (MESI): initial results for a new screening instrument in transplant medicine]. Psychother Psychosom Med Psychol. 2006;56(2):49-55. doi:10.1055/s-2005-867060

58. Klaghofer R, Sarac N, Schwegler K, et al. Fragebogen zur psychischen verabeitung einer organtransplantation: deutsche validierung des transplant effects questionnaire (TxEQ) [Questionnaire on emotional response after organ transplantation: German validation of the transplant effect questionnaire (TxEQ-D)]. Z Psychosom Med Psychother. 2008;54(2):174-188. doi:10.13109/zptm.2008.54.2.174

59. Ziegelmann JP, Griva K, Hankins M, et al. The transplant effects questionnaire (TxEQ): the development of a questionnaire for assessing the multidimensional outcome of organ transplantation - example of end stage renal disease (ESRD). Br J Health Psychol. 2002;7 (Part 4):393-408. doi:10.1348/135910702320645381

60. Mahler C, Jank S, Hermann K, et al. Psychometric properties of a German version of the "Satisfaction with information about medicines scale" (SIMS-D). Value Health. 2009;12(8):1176-1179. doi:10.1111/j.1524-4733.2009.00575.x

61. Horne R, Hankins M, Jenkins R. The satisfaction with information about medicines scale (SIMS): a new measurement tool for audit and research. Qual Health Care. 2001;10(3):135-140. doi:10.1136/ qhc. 0100135

62. Horne R, Weinman J, Hankins M. The beliefs about medicines questionnaire: the development and evaluation of a new method for assessing the cognitive representation of medication. Psychol Health. 1999;14:1-24. doi:10.1080/08870449908407311

Patient Preference and Adherence

\section{Publish your work in this journal}

Patient Preference and Adherence is an international, peer-reviewed, open access journal that focusing on the growing importance of patient preference and adherence throughout the therapeutic continuum. Patient satisfaction, acceptability, quality of life, compliance, persistence and their role in developing new therapeutic modalities and compounds to optimize clinical outcomes for existing disease

Submit your manuscript here: https://www.dovepress.com/patient-preference-and-adherence-journa
63. Mahler C, Hermann K, Horne R, et al. Patients' beliefs about medicines in a primary care setting in Germany. J Eval Clin Pract. 2012;18(2):409-413. doi:10.1111/j.1365-2753.2010.01589.x

64. Bova CA, Fennie KP, Knafl GJ, et al. Use of electronic monitoring devices to measure antiretroviral adherence: practical considerations. AIDS Behav. 2005;9(1):103-110. doi:10.1007/s10461-005-1685-0

65. Belaiche S, Decaudin B, Dharancy S, et al. Factors relevant to medication non-adherence in kidney transplant: a systematic review. Int J Clin Pharm. 2017;39(3):582-593. doi:10.1007/s11096-017-0436-4

66. Leino AD, King EC, Jiang W, et al. Assessment of tacrolimus intrapatient variability in stable adherent transplant recipients: establishing baseline values. Am J Transplant. 2019;19(5):1410-1420. doi:10.1111/ajt.15199

67. Beckebaum S, Iacob S, Sweid D, et al. Efficacy, safety, and immunosuppressant adherence in stable liver transplant patients converted from a twice-daily tacrolimus-based regimen to once-daily tacrolimus extended-release formulation. Transpl Int. 2011;24(7):666-675. doi:10.1111/j.1432-2277.2011.01254.x

68. Doesch AO, Mueller S, Akyol C, et al. Increased adherence eight months after switch from twice daily calcineurin inhibitor based treatment to once daily modified released tacrolimus in heart transplantation. Drug Des Devel Ther. 2013;7:1253-1258. doi:10.2147/DDDT.S52820

69. Tran D, Vallee M, Collette S, et al. Conversion from twice-daily to once-daily extended-release tacrolimus in renal transplant recipients: 2-year results and review of the literature. Exp Clin Transplant. 2014;12(4):323-327. doi:10.6002/ect.2013.0165

70. Considine A, Tredger JM, Heneghan M, et al. Performance of modified-release tacrolimus after conversion in liver transplant patients indicates potentially favorable outcomes in selected cohorts. Liver Transpl. 2015;21(1):29-37. doi:10.1002/lt.24022

71. Gorevski E, Succop P, Sachdeva J, et al. Is there an association between immunosuppressant therapy medication adherence and depression, quality of life, and personality traits in the kidney and liver transplant population? Patient Prefer Adherence. 2013;7:301-307. doi:10.2147/PPA.S34945

72. Dew MA, Posluszny DM, DiMartini AF, et al. Posttransplant medical adherence: what have we learned and can we do better? Curr Transplant Rep. 2018;5(2):174-188. doi:10.1007/s40472-018-0195-8

73. Ladin K, Daniels A, Osani M, et al. Is social support associated with post-transplant medication adherence and outcomes? A systematic review and meta-analysis. Transplant Rev (Orlando). 2018;32 (1):16-28. doi:10.1016/j.trre.2017.04.001

74. Berben L, Dobbels F, Engberg S, et al. An ecological perspective on medication adherence. West J Nurs Res. 2012;34(5):635-653. doi: $10.1177 / 0193945911434518$

75. Feehan M, Morrison MA, Tak C, et al. Factors predicting self-reported medication low adherence in a large sample of adults in the US general population: a cross-sectional study. BMJ Open. 2017;7(6):e014435. doi:10.1136/bmjopen-2016-014435 states are major areas of interest for the journal. This journal has been accepted for indexing on PubMed Central. The manuscript management system is completely online and includes a very quick and fair peer-review system, which is all easy to use. Visit http:// www.dovepress.com/testimonials.php to read real quotes from published authors. 